\title{
BLOCOS DE RELACIONAMENTOS ESTRATÉGICOS NA GESTÃO EMPRESARIAL
}

\author{
Artigo originalmente publicado na Revista de Administração de Empresas da USP - Rausp,
} volume 38, número 3, julho/agosto/setembro 2003

\section{Irene Raguenet Troccoli}

\section{T. Diana L.v.A. de Macedo-Soares}

\section{RESUMO}

Por meio do exemplo de sub-segmento do agronegócio brasileiro no ano de 2003, este artigo é um retrato atemporal da forma como as redes, em especial as de grupos de empresas estruturalmente similares e conectadas mais densamente entre si (blocos estratégicos), podem levar à releitura ou à complementação das análises tradicionais de grupos estratégicos (GEs), porquanto capacitam as empresas a adentrarem esses grupos sem o constrangimento ditado pelas barreiras de mobilidade. Ficou evidenciado que os relacionamentos de um bloco estratégico podem amenizar as ameaças colocadas às empresas em GEs pelas cinco forças estratégicas porterianas - muito embora também possam impor suas próprias ameaças a essas empresas. Também foi demonstrado o quanto a densidade, o padrão, a força e a natureza dos relacionamentos da rede podem, a qualquer época, constituir oportunidades para potencializar o desempenho de empresas em GEs. Ao final, apresentouse uma proposição com base na aplicação dos construtos.

Palavras-chave: Grupos estratégicos. Blocos estratégicos. Redes estratégicas. Alianças estratégicas. Indústria de suco de laranja.

\begin{abstract}
Refering to a Brazilian agribusiness sub-segment in the year 2003, this article is an atemporal portrait of how networks, especially those of groups of firms that are structurally similar and more densely connected to each other, i.e. "strategic blocks", imply reviewing or at least complementing traditional strategic group - SG analyses. The constructs pertinent to the analysis of the strategic implications of networks and blocks for firms in SGs are applied to the case of a group of firms in the Brazilian orange juice industry that is considered, hypothetically, as both strategic group and block. It is shown how they helped reveal that the relationships of blocks can dampen the threats posed by Porter's (1980) five strategic forces to firms in SGs, and to what extent the network's relationships can constitute opportunities in terms of enhancing the performance of firms in SGs.
\end{abstract}

Keywords: Strategic groups. Strategic blocks. Networks of relationships. Strategic alliances. Orangejuice industry. 


\section{INTRODUÇÃO}

Até os anos de 1980, as empresas foram dominadas pelo conceito da rivalidade, em consonância com as condições que, então, imperavam: produção em massa, existência de mercados oligopólicos, baixa competição estrangeira, ciclo de vida de produto longo, demanda baixa por novas tecnologias e menor custo de capital.

Porém, no final daquela década, o mundo passou por uma mudança radical, definida como globalização. A economia, agora caracterizada por maior liberalização dos mercados, começou a basear-se, de forma crescente, em conhecimento menos explícito, que não pode ser transferido simplesmente por meio de licenças ou compras. Simultaneamente, a competição intensificava-se, e a posse de todos os recursos necessários não raro passava a ser menos importante do que lhes ter o acesso. Os consumidores, por sua vez, aumentaram suas exigências, requerendo contato mais estreito com as empresas, que começaram a preocuparse com a customização.

Nesse contexto, a empresa viu-se impelida a desenvolver funções situadas fora dos seus limites tradicionais, consciente de que maior chance de sucesso teria aquela que pudesse atuar de forma mais ágil do que as concorrentes, garantindo para si mesma uma vantagem de posicionamento. A conseqüente busca por uma postura mais concentrada nos respectivos negócios centrais explica o porquê do florescimento, na última década e meia, da tendência à construção de alianças entre empresas: foi a forma encontrada para se criarem relações entre organizações dissimilares, mas cujas sortes positivamente relacionadas fortalecem a colaboração (PECI, 1999).

Por esses motivos, as alianças e redes estratégicas vêm sendo pesquisadas de forma crescente no campo da Administração de Empresas. Neste artigo, tenciona-se contribuir para essas pesquisas, mostrando como as redes estratégicas, especialmente as de grupos de empresas estruturalmente similares e mais densamente conectadas entre si, ou seja, blocos estratégicos, conforme proposto por Nohria \& Garcia-Pont (1991), implicam uma releitura ou complementação das análises tradicionais de grupos estratégicos (GEs), porque capacitam as empresas a adentrarem esses grupos sem o constrangimento tradicionalmente ditado pelas barreiras de mobilidade.

0 artigo foi estruturado em cinco partes, além desta introdução. Nas duas primeiras, com base em pesquisa bibliográfica, explicam-se conceitos-chave. $\mathrm{Na}$ seguinte, apresentam-se construtos pertinentes à análise das implicações estratégicas de blocos para empresas em GEs. Na quarta, compartilham-se os resultados da aplicação desses construtos, com auxílio de levantamento documental, ao caso de um agrupamento de empresas na agroindústria brasileira de suco de laranja situado no final do ano de 2001, considerado, por hipótese, como sendo simultaneamente grupo e bloco estratégicos, de acordo com o conceito de pooling block de Nohria \& Garcia-Pont (1991). Buscou-se, assim, a validação dos construtos, no sentido de poderem fornecer subsídios para a tomada de decisão estratégica de empresas em GEs que possam complementar os resultados de análises tradicionais. Por último, apresenta-se uma proposição com base na aplicação dos construtos, a ser validada por pesquisa empírica futura, junto com a hipótese do caso de GE escolhido, e lançam-se sugestões para novas investigações.

\section{SEGMENTAÇÃO DE UMA INDÚSTRIA EM GRUPOS E BLOCOS ESTRATÉGICOS}

\section{Definição de grupos estratégicos}


O conceito de GEs surgiu no final dos anos de 1970, como resultado de investigações empíricas em vários ramos industriais, objetivando auxiliar a análise das diferenças na lucratividade entre as empresas do mesmo setor, ao representar um nível intermediário de análise entre a empresa e a indústria como um todo (FIEGENBAUM \& THOMAS, 1993). Aqui, a definição de GE inspira-se em Cool \& Schendel (1987): um grupo de empresas competindo em uma indústria à base de combinações semelhantes de compromissos de escopo e de recursos, de modo independente ou não.

\section{Definição de blocos estratégicos}

Nohria \& Garcia-Pont (1991) verificaram a possibilidade de uma visão complementar na análise dos GEs. Sugeriram um nível intermediário entre conjuntos de empresas de uma indústria, que sejam estruturalmente similares e mais densamente conectadas entre si do que com as demais e com a rede total que as integra. Denominando essas empresas de bloco estratégico (BE), propuseram um continuum de tipos ideais de blocos em que um dos extremos seria ocupado por bloco no qual todas as empresas pertenceriam ao mesmo GE (pooling block) e o outro extremo por bloco em que cada membro pertenceria a GEs diferentes (complementary block).

A utilização do conceito de BE é oportuna dada a sua abrangência, que permite tornar mais inteligível a complexidade envolvida em ambiente caracterizado por redes de alianças estratégicas. No entanto, propõe-se, aqui, uma extensão a esse conceito, para permitir uma análise relacional que transcenda as fronteiras de um setor econômico, de modo a proporcionar entendimento ainda mais completo do comportamento estratégico das empresas envolvidas. Consiste em considerar-se que, em uma indústria composta por mais de um subsetor, se possa ter,em um desses subsetores, um bloco estratégico identificado por conexões entre as empresas quese originem de suas atuações em outro subsetor.

Antes de tratar das implicações estratégicas das alianças e redes para os GEs, cabe deixar claro o que se entende aqui por alianças e redes.

\section{CONCEITOS DE ALIANÇAS E DE REDES ESTRATÉGICAS}

\section{Alianças}

Considerada de maneira ampla como "acordos voluntários entre empresas envolvendo a troca, o compartilhamento ou o co-desenvolvimento de produtos, tecnologias ou serviços" (GULATI, 1998, p.293), a aliança é definida, aqui, como um relacionamento estabelecido entre duas ou mais partes, que visa a um compartilhamento do conhecimento e de outros recursos, que possa ser benéfico para todos os envolvidos. Nem sempre uma aliança é estratégica, só adquirindo essa qualificação quando estabelecida com vistas à manutenção ou à criação de vantagem competitiva.

\section{Redes Estratégicas}

Quanto a redes estratégicas, adota-se a definição de Gulati, Nohria \& Zaheer (2000, p.203): "um conjunto de relacionamentos da empresa, tanto horizontais como verticais, com outras organizações - fornecedores, clientes, concorrentes e outras entidades -, incluindo relações que atravessam as fronteiras de indústrias e países. São compostas por laços 
interorganizacionais duradouros, de significado estratégico, e incluem alianças entre empresas e demais entidades" 1 .

Contribuindo para a pesquisa em estratégia, Galaskiewicz \& Zaheer (1999) identificaram três dimensões-chave pertinentes às redes - estrutura, modalidade e composição -, cujas características podem influenciar a conduta e o desempenho de empresas que atuam em rede.

Gulati, Nohria \& Zaheer (2000), por sua vez, mostraram como essas dimensões podem auxiliar na análise das implicações estratégicas da rede tanto no nível da indústria - ao representarem oportunidades e ameaças - quanto no da empresa - ao constituírem-se em forças e fraquezas.

Neste artigo, o foco recairá sobre as ameaças e oportunidades relacionais, em uma análise no nível da indústria, precisamente no dos GE em uma determinada indústria, por meio do conceito de blocos estratégicos. Parte-se do pressuposto de que a capacidade das empresas de administrar as ameaças e aproveitar as oportunidades é fator crítico do seu sucesso estratégico.

\section{Alianças e redes em ambiente de grupos estratégicos}

A estrutura de uma rede de alianças estratégicas assume papel importante tanto para o desempenho da empresa quanto para a evolução da própria indústria, conforme facilita ou dificulta a habilidade de empresas específicas em determinar o desenvolvimento da indústria. Há uma tendência natural de mesclarem-se as habilidades individuais - resultados de esforços estratégicos de longo prazo realizados pelas empresas - com vistas à consolidação de um conjunto de recursos e capacitações cujos benefícios se socializam entre os componentes da rede. Essa estrutura beneficiada por esses intercâmbios, ao possibilitar a imitação de capacidades estratégicas desejadas, revela-se uma forma eficiente de suplantação das barreiras de mobilidade que, tradicionalmente, dificultavam a migração de uma empresa de um grupo para outro.

Portanto, o conceito de redes convida a que a análise do desempenho de empresas em GEs complemente a tradicional configuração centrada em fatores estruturais da indústria, conforme modelo de Porter (1980), e nos fatores macroambientais interagentes (AUSTIN, 1990) ou em recursos e competências, de acordo com a visão Resource-Based (WERNERFELT, 1984). Da mesma forma, remete a uma releitura do conceito das barreiras de mobilidade enquanto construto relevante ao desempenho dessas empresas. Isso porque, se as alianças e redes visam eliminar as dificuldades estruturais de acesso das empresas a recursos-chave, ipso facto elas podem contribuir para melhorar as condições sob as quais poderia ocorrer a entrada de uma empresa em um grupo estratégico ou a migração de uma empresa de um grupo para outro. Esse fenômeno, por sua vez, tende a influenciar o contexto de ameaças e oportunidades que as empresas tradicionalmente teriam de administrar, devido às óbvias conseqüências que esse trânsito facilitado pode ter sobre o desempenho organizacional. Em outras palavras, essa nova ótica permite, por meio do conceito de bloco estratégico, complementar a teoria dos GEs no que concerne ao papel das barreiras de mobilidade.

\section{Teoria das barreiras de mobilidade}

\footnotetext{
1 Tradução das autoras.
} 
As barreiras de mobilidade surgiram como uma extensão, em nível dos GEs, do conceito de barreiras de entrada na indústria, à medida que limitam a entrada, no grupo, de empresas com configurações estruturais similares, conforme retardem ou dificultem a imitação (CAVES \& PORTER, 1977). Em outras palavras, são fatores que dissuadem os movimentos de empresas de uma posição estratégica para outra.

\section{CONSTRUTOS PARA A ANÁLISE DAS IMPLICAÇõES DAS REDES DE GRUPOS ESTRATÉGICOS}

\section{Dinâmicas intra e intergrupal pela ótica das redes e alianças estratégicas}

Para Barney (1996), estratégia refere-se às ações da empresa que visam responder às ameaças e às oportunidades em seu meio ambiente, ao mesmo tempo em que exploram suas forças e evitam ou amenizam suas fraquezas. Adaptando o conceito de boa estratégia desse autor para o caso de análise de adequação estratégica na ótica relacional, Macedo-Soares (2002, p. 294) postula que: "a estratégia só pode ser considerada adequada quando capitaliza nas forças constituídas, não meramente nos recursos internos à empresa e nas condições organizacionais necessárias para gerenciá-los, mas também nos recursos fornecidos pela rede de relacionamentos, amenizando fraquezas pertinentes tanto à empresa quanto à rede. Tratase de explorar não apenas as oportunidades macroambientais, mas também aquelas apresentadas pela rede, minimizando ameaças eventuais criadas tanto pelo macroambiente como pela rede"2.

Essa busca por adequação entre recursos e outros fatores organizacionais, por um lado, e oportunidades e ameaças, por outro, implica que as empresas realizem desde grandes mudanças estratégicas até pequenos ajustes táticos. As próprias condições derivadas do momento econômico podem afetar a entrada das empresas nos grupos estratégicos, mas esses determinantes da dinâmica dos GEs não eliminam o entrave natural à sua efetivação representado pelas barreiras de mobilidade, conforme Caves \& Porter (1977). É nesse momento que os relacionamentos interempresas surgem como uma forma de não apenas ajudar a administrar esses períodos de incerteza como de canalizar os benefícios possibilitados pelo controle e pela informação proporcionados pela rede, visto que esses são canais pelos quais os bens e os serviços são acessados.

Os recursos que as empresas podem adquirir ao participarem de redes estratégicas bem estruturadas, tais como os blocos estratégicos, capacitam-nas a obter retornos superiores em multiplicidade de ambientes, formando um valioso capital social que se configura em uma força poderosa na busca da vantagem competitiva. Ademais, esse tipo de configuração em rede tem a capacidade de estimular novas alianças, em conseqüência do contato prolongado entre os parceiros (ANAND \& KHANNA, 2000).

\section{Construtos para a análise das implicações estratégicas de redes e blocos para GEs}

Na medida em que a ótica relacional e, em particular, o conceito de bloco estratégico permitem uma releitura do papel das barreiras de mobilidade críticas ao desempenho das empresas em GEs, tornam-se relevantes construtos para as dimensões relacionais pertinentes a essas barreiras. Como a análise relacional concentra-se, aqui, nos blocos, esses construtos se referem à rede do bloco. Eles são elencados a seguir.

2 Tradução das autoras. 
- Dimensões estruturais da rede do bloco: densidade (alta ou baixa), posição (central ou periférica), centralidade (alta ou baixa), escopo (amplo ou estreito, variado ou pouco, global ou local). Quando a densidade da rede é alta, há grande envolvimento mútuo dos membros do bloco, ou seja, laços inter-empresariais densos. Redes coesas são importantes para o desenvolvimento de capital social (COLEMAN, 1988). Quando o bloco ocupa uma posição central na rede, e essa centralidade é alta, para ele se dirigem os fluxos de informação diretos e indiretos, já que ele se encontra na confluência de múltiplas passagens de recursos. 0 aprendizado é maior, assim como a capacidade de desenvolver capacitações diferenciadas, que implicam vantagem relativamente grande aos potenciais entrantes no bloco. Se o escopo (alcance) da rede em que o bloco se insere é amplo, variado e global, ocorrem benefícios da diversidade material, de informação, de habilidades e de outros recursos às empresas que compõem o bloco, facultando-lhes a criação de valor e maior capacidade concorrencial.

- Dimensões da modalidade da rede do bloco: padrão, força e natureza das ligações (diretas ou indiretas, fortes ou fracas, colaborativas ou oportunistas, múltiplas ou únicas). Quando as ligações em rede do bloco são diretas, fortes, colaborativas e múltiplas, há aproveitamento total dos benefícios das interações, uma vez que os atores estão em busca da vantagem comum. Esses se comportam de forma confiável uns com os outros e honram suas obrigações, intercambiam informações úteis e observam normas que colocam os interesses coletivos acima dos interesses particulares.

- Dimensões da composição da rede do bloco: identidade e status das empresas no bloco e dos seus parceiros (identidade forte e status elevado ou identidade fraca e status baixo), acesso a recursos das empresas no bloco e dos parceiros (fácil ou difícil). É intuitivo que, quanto mais forte a identidade e mais elevado o status do bloco, maiores as vantagens reais e potenciais que podem surgir dos relacionamentos entre as empresas que o compõem, em função da posição dominante detida pelos atores. Uma rede será beneficiada sempre que contar com a presença de bloco formado por empresas que tenham fácil acesso a recursos (por exemplo, materiais, informacionais, de habilidades), de modo a complementarem-se umas às outras, agregando valor às transações mútuas.

Já no que tange à ereção de barreiras de saída às empresas situadas em bloco, pela ótica relacional todos os construtos remetem a um fenômeno: conforme uma rede se torna mais densa, os membros do bloco tendem a um comprometimento crescente de seus recursos. Esse processo torna mais difícil tanto seu desvencilhamento dessas relações como a visualização de oportunidades de negócios fora da rede em que se insere o bloco - o que é potencializado pelo fato de, por definição, a rede do bloco possuir maior densidade do que as redes verificadas fora dele (NOHRIA \& GARCIA-PONT, 1991).

Essas considerações reforçam o argumento de que as redes - e, especialmente, o conceito de blocos estratégicos - podem complementar a análise tradicional de GEs.

A seguir, aplicam-se os construtos pertinentes à análise estratégica de GEs, na ótica relacional, a um caso eleito hipoteticamente, com base em investigação documental, como ilustrativo do conceito de pooling block proposto por Nohria \& Garcia-Pont (1991). A escolha de grupo que coincide com bloco é proposital, pois permite comparar as implicações estratégicas pela perspectiva relacional (caso dos blocos) com aquelas observadas pela perspectiva tradicional 
(caso dos grupos).

\section{APLICAÇÃO DOS CONSTRUTOS PARA A ANÁLISE DOS GRUPOS ESTRATÉGICOS PELA PERSPECTIVA RELACIONAL}

Os dados relativos à economia citrícola, para análise do GE escolhido para a aplicação dos construtos, foram levantados nos trabalhos de Azevedo (1996; 1997), Di Giorgi (1994), Margarido (1996) e Marino (2001), bem como em relatórios dos arquivos do Centro de Estudos Agrícolas da Fundação Getulio Vargas (FGV). Cabe mencionar que o caso em questão faz referência a um momento específico da agroindústria brasileira de suco de laranja não concentrado (SLNC) - o final do ano de 2001 -, não contemplando as mudanças posteriores ocorridas nesse setor. Essa restrição não diminui a validade do caso para ilustrar a capacidade de agregação de valor da mencionada perspectiva relacional à tradicional.

\section{A agroindústria brasileira de suco de laranja não concentrado (SLNC) em 2001}

Em 2001, a agroindústria brasileira de suco de laranja era composta por três segmentos, sendo dois de sucos pasteurizados - o suco de laranja concentrado congelado (SLCC) e o suco de laranja não concentrado (SLNC) - e um de não pasteurizado - o chamado suco fresco, obtido tanto em micro-extratoras como de forma artesanal (doméstica). Dada a impossibilidade de quantificação desse último, devido à sua pulverização espacial, ele não fará parte deste estudo, que estará restrito apenas aos dois primeiros segmentos.

O SLCC é o suco de laranja do qual se extraiu água até chegar-se à concentração de $65^{\circ}$ Brix (65\% de sólidos solúveis e 35\% de água); sua produção existe no Brasil há cerca de 30 anos, e constitui-se na maior do mundo.

Já o SLNC se estabeleceu há pouco mais de meia década e conta com cifras bem menos expressivas. Trata-se do suco industrializado, pasteurizado, refrigerado, acondicionado em embalagem tetra pak, sem adição de água ou de açúcar. Com shelf life limitada a alguns dias e a necessidade de ser mantido a baixas temperaturas, requer não só uma estrutura de distribuição refrigerada, mas também uma forte expertise na logística dessa atividade que garanta o ritmo do abastecimento sem interrupções e sem perda de qualidade da bebida.

O mercado brasileiro de SLNC foi inaugurado, nos anos de 1990, pela Parmalat (TROCCOLI, 1996), beneficiando-se do fato de ser empresa laticinista e, portanto, fortemente especializada em distribuição refrigerada ${ }^{3}$. Em seguida, adentraram esse segmento empresas não produtoras de SLCC, mas formadas a partir de algum tipo de ligação prévia com a citricultura (por exemplo,produção de laranja) ou com outro ramo do agribusiness.

Duas outras grandes empresas com foco central tradicionalmente na produção do SLCC para exportação - Cargill e Citrovita - também se interessaram pelo SLNC (TROCCOLI, 1999), estimuladas pela desvalorização das cotações do SLCC (devido a fatores inerentes à oferta e à demanda desse mercado, ocorridos no biênio 1993/1994 e em 1997) e pela expansão do mercado interno do SLNC. No entanto, elas não detinham competência alguma em distribuição no mercado interno, nem os ativos necessários à distribuição refrigerada, nem marca que pudessem dar aos seus sucos. Em outros termos, defrontavam-se com fortes

\footnotetext{
${ }^{3}$ Posteriormente, a Parmalat passou a fabricar o SLNC em bases não constantes, adquirindo-o eventualmente de terceiros.
} 
barreiras de entrada para moverem-se do GE-SLCC e adentrarem o GE-SLNC para o mercado interno.

Para contornarem essas barreiras, constituíram alianças estratégicas de marketing com laticinistas concorrentes da Parmalat que não possuíam o SLNC em seus portfolios, mas que detinham marcas varejistas conhecidas e dominavam a logística da distribuição refrigerada 4 . Essas alianças foram constituídas por meio de contratos de tempo limitado entre as partes, com a Cargill e a Citrovita tornando-se meros prestadores de serviço aos laticinistas, que não interferiam nas etapas posteriores de distribuição e vendas.

Por meio das parcerias com os laticinistas, a Citrovita e a Cargill, que já se situavam em uma extensa rede no mercado de SLCC, passaram a também se situar em rede no ambiente de SLNC - englobando, por exemplo, embaladores, laticinistas, supermercadistas e consumidores finais. Com isso, até novembro de 2001, os produtores de SLNC para o mercado interno eram a Cargill, a Citrovita e algumas empresas de menor porte e, muitas vezes, com foco mais regional $^{5}$. Tomando-se por base a definição de GE inspirada em Cool \& Schendel (1987), por hipótese elegeram-se dois GEs-SLNC.

- Citrovita e Cargill: competiam na indústria brasileira de SLNC à base de interesse paralelo nesse mercado, já que seu core business era o SLCC, mercado em que apresentavam comportamento cooperativo que pode ser identificado em ações pontuais, como, por exemplo, “... joint ventures para exploração de terminais (portuários) no exterior, reduzindo assim os investimentos e a capacidade ociosa. Existe uma coordenação interna do setor (de SLCC) que permite maximizar a utilização destes terminais pelas empresas-líderes..." (MARINO, 2001, p.46).

Por isso, esse GE foi considerado, por hipótese, um bloco estratégico identificado por conexões que se originavam de suas atuações no nível da agroindústria de SLCC (fenômeno que remete à extensão proposta no conceito de bloco estratégico). Devido a essa particularidade, no caso sob estudo, o foco relacional, embora concentrado na agroindústria de SLNC, transcendeu as fronteiras desse ambiente, também contemplando a influência do relacionamento do grupo estratégico Cargill/Citrovita (GCC) com as demais empresas produtoras de SLCC e entre si. Como esse grupo é também considerado aqui um bloco estratégico, o GCC referiu-se igualmente ao bloco estratégico Cargill/Citrovita.

- Outras empresas: detinham algum tipo de convivência anterior com a citricultura ou de familiaridade pré-existente com o agribusiness; às vezes, utilizavam seu foco geográfico de distribuição menos extenso e seu porte menor do que o das três outras empresas como indicadores de maior qualidade da bebida. As empresas proeminentes nesse grupo no estado de São Paulo eram, no final de 2001, a Sun Home, a Hildebrand e Grupo Nova América.

\section{A agroindústria brasileira de suco de laranja não concentrado (SLNC) em 2001}

\footnotetext{
4 Até novembro de 2001, a Cargill fabricava para o laticinista Leite Paulista, enquanto o SLNC da Citrovita era distribuído por Fazenda Bela Vista, Salute, Danone, Da Granja e Leco-Vigor. A partir desse mês, a Citrovita manteve a fabricação do SLNC apenas para a Leco-Vigor.

5 Uma dessas empresas de menor porte (Hildebrand) também mantinha parceria com laticinista para a distribuição de suco de laranja; porém, por tratar-se de variedade de diluído de concentrado e adoçado, não constituiu objeto de estudo nesta pesquisa.
} 
Em 2001, a agroindústria brasileira de suco de laranja era composta por três segmentos, sendo dois de sucos pasteurizados - o suco de laranja concentrado congelado (SLCC) e o suco de laranja não concentrado (SLNC) - e um de não pasteurizado - o chamado suco fresco, obtido tanto em micro-extratoras como de forma artesanal (doméstica). Dada a impossibilidade de quantificação desse último, devido à sua pulverização espacial, ele não fará parte deste estudo, que estará restrito apenas aos dois primeiros segmentos.

O SLCC é o suco de laranja do qual se extraiu água até chegar-se à concentração de $65^{\circ}$ Brix (65\% de sólidos solúveis e 35\% de água); sua produção existe no Brasil há cerca de 30 anos, e constitui-se na maior do mundo.

Já o SLNC se estabeleceu há pouco mais de meia década e conta com cifras bem menos expressivas. Trata-se do suco industrializado, pasteurizado, refrigerado, acondicionado em embalagem tetra pak, sem adição de água ou de açúcar. Com shelf life limitada a alguns dias e a necessidade de ser mantido a baixas temperaturas, requer não só uma estrutura de distribuição refrigerada, mas também uma forte expertise na logística dessa atividade que garanta o ritmo do abastecimento sem interrupções e sem perda de qualidade da bebida.

O mercado brasileiro de SLNC foi inaugurado, nos anos de 1990, pela Parmalat (TROCCOLI, 1996), beneficiando-se do fato de ser empresa laticinista e, portanto, fortemente especializada em distribuição refrigerada ${ }^{6}$. Em seguida, adentraram esse segmento empresas não produtoras de SLCC, mas formadas a partir de algum tipo de ligação prévia com a citricultura (por exemplo, produção de laranja) ou com outro ramo do agribusiness.

Duas outras grandes empresas com foco central tradicionalmente na produção do SLCC para exportação - Cargill e Citrovita - também se interessaram pelo SLNC (TROCCOLI, 1999), estimuladas pela desvalorização das cotações do SLCC (devido a fatores inerentes à oferta e à demanda desse mercado, ocorridos no biênio 1993/1994 e em 1997) e pela expansão do mercado interno do SLNC. No entanto, elas não detinham competência alguma em distribuição no mercado interno, nem os ativos necessários à distribuição refrigerada, nem marca que pudessem dar aos seus sucos. Em outros termos, defrontavam-se com fortes barreiras de entrada para moverem-se do GE-SLCC e adentrarem o GE-SLNC para o mercado interno.

Para contornarem essas barreiras, constituíram alianças estratégicas de marketing com laticinistas concorrentes da Parmalat que não possuíam o SLNC em seus portfolios, mas que detinham marcas varejistas conhecidas e dominavam a logística da distribuição refrigerada ${ }^{7}$. Essas alianças foram constituídas por meio de contratos de tempo limitado entre as partes, com a Cargill e a Citrovita tornando-se meros prestadores de serviço aos laticinistas, que não interferiam nas etapas posteriores de distribuição e vendas.

Por meio das parcerias com os laticinistas, a Citrovita e a Cargill, que já se situavam em uma extensa rede no mercado de SLCC, passaram a também se situar em rede no ambiente de SLNC - englobando, por exemplo, embaladores, laticinistas, supermercadistas e consumidores finais.

\footnotetext{
6 Tradução das autoras.

${ }^{7}$ Até novembro de 2001, a Cargill fabricava para o laticinista Leite Paulista, enquanto o SLNC da Citrovita era distribuído por Fazenda Bela Vista, Salute, Danone, Da Granja e Leco-Vigor. A partir desse mês, a Citrovita manteve a fabricação do SLNC apenas para a Leco-Vigor.
} 
Com isso, até novembro de 2001, os produtores de SLNC para o mercado interno eram a Cargill, a Citrovita e algumas empresas de menor porte e, muitas vezes, com foco mais regional $^{8}$. Tomando-se por base a definição de GE inspirada em Cool \& Schendel (1987), por hipótese elegeram-se dois GEs-SLNC.

- Citrovita e Cargill: competiam na indústria brasileira de SLNC à base de interesse paralelo nesse mercado, já que seu core business era o SLCC, mercado em que apresentavam comportamento cooperativo que pode ser identificado em ações pontuais, como, por exemplo, “... joint ventures para exploração de terminais (portuários) no exterior, reduzindo assim os investimentos e a capacidade ociosa. Existe uma coordenação interna do setor (de SLCC) que permite maximizar a utilização destes terminais pelas empresas-líderes..." (MARINO, 2001, p.46).

Por isso, esse GE foi considerado, por hipótese, um bloco estratégico identificado por conexões que se originavam de suas atuações no nível da agroindústria de SLCC (fenômeno que remete à extensão proposta no conceito de bloco estratégico). Devido a essa particularidade, no caso sob estudo, o foco relacional, embora concentrado na agroindústria de SLNC, transcendeu as fronteiras desse ambiente, também contemplando a influência do relacionamento do grupo estratégico Cargill/Citrovita (GCC) com as demais empresas produtoras de SLCC e entre si. Como esse grupo é também considerado aqui um bloco estratégico, o GCC referiu-se igualmente ao bloco estratégico Cargill/Citrovita.

- Outras empresas: detinham algum tipo de convivência anterior com a citricultura ou de familiaridade pré-existente com o agribusiness; às vezes, utilizavam seu foco geográfico de distribuição menos extenso e seu porte menor do que o das três outras empresas como indicadores de maior qualidade da bebida. As empresas proeminentes nesse grupo no estado de São Paulo eram, no final de 2001, a Sun Home, a Hildebrand e Grupo Nova América.

\section{Ameaças e oportunidades ao grupo Cargill/Citrovita pela ótica relacional}

A ótica relacional para a análise das ameaças e oportunidades no caso do GCC é uma inovação à perspectiva tradicional. Nessa última, apenas as implicações antagônicas das cinco forças porterianas - novos entrantes, rivais, fornecedores, compradores e substitutos - e dos fatores macroambientais interagentes seriam contempladas, estudadas pelo ângulo da geração de oportunidades, ameaças e barreiras de mobilidade aos atores envolvidos, quando aquelas forças são exercidas. Já na análise relacional do caso do GCC - ou seja, aqui enquanto bloco estratégico - foram avaliadas as influências das características de redes no caso especial de empresas que são estruturalmente similares e mais conectadas entre si do que com as demais, e que, enquanto pooling block, pertencem ao mesmo grupo estratégico.

Essa avaliação permitiu identificar as seguintes ameaças e oportunidades:

\section{Ameaças}

\footnotetext{
${ }^{8}$ Uma dessas empresas de menor porte (Hildebrand) também mantinha parceria com laticinista para a distribuição de suco de laranja; porém, por tratar-se de variedade de diluído de concentrado e adoçado, não constituiu objeto de estudo nesta pesquisa.
} 
- Muito baixa densidade na rede entre o bloco Cargill/Citrovita e os laticinistas gerando relativo desinteresse de ambas as partes em perpetuar o relacionamento, facultando a entrada de outros atores como substitutos de qualquer lado.

- Escopo estreito e local na rede entre o bloco e os laticinistas, e entre os laticinistas e os distribuidores varejistas, implicando relativo desinteresse do bloco em perpetuar o relacionamento, facultando a entrada de outros atores como substitutos no fornecimento de SLNC aos laticinistas, e como substitutos na distribuição às empresas que compõem o bloco;também implicando ausência do SLNC dos canais alternativos que pudessem aumentar sua capacidade concorrencial.

- Ligações relativamente fracas, oportunistas e não-múltiplas entre o bloco e os laticinistas implicando ausência de maior solidez nas alianças e possibilidade de rompimento fortuito do contrato de fornecimento do SLNC, gerando baixo interesse do bloco em permanecer em rede com os laticinistas.

- Identidade forte e status elevado no bloco devido à sua atuação tradicional e consistente no SLCC causando sobreposição dos interesses do SLCC aos do SLNC, o que poderia desmotivar a permanência do bloco nesse último.

- Acesso difícil por parte do bloco aos recursos dos parceiros laticinistas desmotivando a manutenção das alianças de distribuição.

\section{Oportunidades}

- Densidade alta na rede dentro do bloco Cargill/Citrovita, e entre esse bloco e as demais empresas produtoras de SLCC, refletindo-se em coordenação interna no setor de SLCC, implicando reflexos positivos no mercado de SLNC.

- A posição central, tanto das empresas que compunham o bloco como dos respectivos laticinistas distribuidores, facilitava a penetração do SLNC nos pontos-de-venda devido à ampla linha de lácteos dos laticinistas e à força de suas marcas; ademais, o bloco beneficiavase, no SLNC, de vantagens em nível operacional oriundas do mercado de SLCC (maior facilidade no acesso à matéria-prima, por exemplo)

- A elevada centralidade que detinham tanto as empresas que compunham o bloco quanto os laticinistas distribuidores devido ao status de suas marcas - apresentando conexões com muito mais parceiros do que as conexões apresentadas por rivais menos centrais - trazia benefícios em todas as etapas de produção e de distribuição do SLNC, resultando no oferecimento de produto de elevada qualidade e distribuído de forma adeqüada às suas características de perecibilidade.

- O escopo amplo, variado e global na rede dentro do bloco, e entre esse bloco e as demais empresas produtoras de SLCC, refletia-se em benefícios nos custos/competitividade no mercado de SLNC.

- As ligações fortes, colaborativas e múltiplas entre as empresas que compunham o bloco, derivadas da cooperação que imperava entre os fabricantes no mercado de SLCC, refletiam-se positivamente no mercado de SLNC.

- A identidade forte e o status elevado do GCC, devido à sua atuação tradicional e consistente no SLCC (as empresas do bloco fazem parte do grupo das cinco maiores 
produtoras/exportadoras brasileiras de SLCC), facilitavam a atuação do bloco em qualquer segmento da indústria de suco de laranja.

- A identidade forte e o status elevado dos distribuidores laticinistas devido à tradição, à força das marcas e à ampla linha de produtos, diminuíam a atratividade à entrada de novos atores distribuidores (que deveriam dispor das mesmas qualificações elevadas na distribuição do SLNC) e facilitavam a penetração do SLNC nos pontos-de-venda varejistas tradicionais.

- O acesso fácil a recursos no bloco, devido à sua forte atuação no mercado de SLCC, possibilitava a obtenção de menores custos no SLNC do que os dos concorrentes.

Em síntese, as ameaças às empresas, aqui consideradas como o grupo GCC e analisadas como constituindo um bloco no mercado de SLNC, residiam nas características de densidade, de escopo, da modalidade das ligações e do acesso a recursos de parceiros da rede maior em que o bloco se encontra. Isso ocorria fundamentalmente porque os relacionamentos entre as empresas do GCC e os laticinistas se limitavam a alianças de marketing - ou seja, havia nítida separação entre os negócios de produção (que cabiam às empresas do GCC) e de distribuição (que cabiam aos laticinistas). Essa particularidade facilitava a substituição do fabricante, facultando a entrada de empresas de SLNC que desejassem tornar-se fornecedoras - o que era reforçado pelo fato de essa bebida ser, basicamente, uma commodity (AZEVEDO, 1997).

Exemplo disto ocorreu quando a Citrovita desejou interromper o fornecimento de SLNC a quatro dos laticinistas aos quais servia em fins de 2001: não houve dificuldades para a substituição por outras empresas, com a Nova América rapidamente passando a responsabilizar-se por quatro marcas e a Cargill por uma. Já pelo lado das características da rede que favoreciam a permanência das empresas do GCC no mercado de SLNC, desestimulando a entrada de concorrentes, elas apoiavam-se, fundamentalmente, nas vantagens que essas empresas tinham enquanto bloco estratégico. Derivavam de aspectos relativos à produção da bebida, oriundas das características da rede do próprio bloco em termos de densidade, posição, centralidade, escopo, ligações, identidade e status, e de acesso a recursos, que permeavam seus relacionamentos. Por exemplo, as ligações que as empresas do GCC mantinham entre si enquanto bloco estratégico, derivadas dos negócios de SLCC, geravam-lhes vantagens em termos estratégicos no mercado de SLNC, como no caso de garantir tanto o fornecimento ininterrupto como o preço mais baixo da matéria-prima laranja. Em outras palavras, seu envolvimento em redes específicas ao setor de SLCC implicava reflexos positivos sobre o mercado de SLNC, gerando maiores facilidades, comparativamente aos membros de outros GEs da mesma indústria. Nesse sentido, tornava-se mais difícil a entrada de novos produtores no segmento dessa bebida, porquanto esses deveriam apresentar semelhantes recursos produtivos em termos de capacidade de produção para poderem competir em igualdade de condições.

Ainda no que se refere à composição da rede, a forte identidade e o elevado status dos parceiros constituíam-se em oportunidades para as empresas do GCC, tendo em vista as sólidas ligações existentes entre os laticinistas e as cadeias varejistas em que tinham penetração. Sua ligação com laticinistas detentores de marcas de reputação não só as colocava em vantagem diante das demais ofertantes de SLNC, que não a Parmalat, como também inibia a entrada de novos atores nesse mercado.

Com isso, ambas as empresas do GCC adquiriram o que Gulati, Nohria \& Zaheer (2000) chamam de recursos de rede: conceito semelhante ao de capital social, remete ao fato de a 
rede ser fonte de criação de valor inimitável e não-substitutível. Embora esses autores advirtam que, nesse tipo de alavancagem de segundo nível, seja limitada a intencionalidade possível por parte da empresa focal, é lícito propor-se que as empresas do GCC se beneficiavam do fato de estarem em rede com laticinistas detentores de marcas varejistas de reputação, já que esses tinham presença facilitada em cadeias conceituadas de distribuição.

\section{Implicações relacionais às ameaças enfrentadas pelas empresas do GCC pela ótica tradicional}

As ameaças às empresas aqui consideradas por hipótese como constituindo o GCC pela ótica tradicional foram resumidas por Troccoli \& Macedo-Soares (2001) em doze pontos. Esses são apresentados, a seguir, juntamente com a análise de o quanto as ameaças poderiam ser amenizadas pelo fato de essas empresas se constituírem em bloco estratégico e de terem, assim, relacionamentos entre si, com os laticinistas distribuidores e com as demais empresas produtoras de SLCC.

- Insuficiente controle das doenças que afetavam os pomares - a alta densidade da rede entre as empresas do GCC e dessas com as demais produtoras de SLCC levou-as a impulsionarem o Fundecitrus ${ }^{9}$ e a intensificarem a colaboração com órgãos estatais dedicados à pesquisa fitossanitária.

- Baixo nível de instrução da mão-de-obra utilizada na colheita de laranjas - esse baixo nível podia afetar a eficiência da mão-de-obra empregada na lavoura. Ao analisarem os determinantes da produtividade total de fatores na agricultura brasileira no período de 1970 a 1995, Vicente, Anefalos \& Caser (2001) confirmaram a importância da educação (entendida como sinônimo de escolaridade) da população rural para a produtividade agrícola. Na conclusão de sua pesquisa, esses autores afirmaram: "A escolaridade da população rural aparenta ser fator essencial para a produção eficiente na agricultura, ressaltando a importância de investimentos em educação para o aumento da competitividade, mesmo no setor primário da economia" (p. 6). No caso da citricultura paulista, tratava-se de uma ameaça paradoxal, pois essa característica da mão-de-obra era encarada com complacência pelas empresas processadoras de laranja. Ao permitir salários baixos vis-à-vis aqueles praticados no Primeiro Mundo, representava menores custos, implicando vantagem competitiva para o SLCC no exterior. Nesse sentido, não havia esforço por parte da rede em amenizar essa ameaça.

- Deficiências na infra-estrutura do País - a alta densidade da rede entre as empresas do GCC e dessas com as demais produtoras de SLCC levou-as a organizarem-se na busca pelas soluções para essas deficiências.

- Desatualização do pacote tecnológico disponível à lavoura citrícola - a alta densidade da rede entre as empresas do GCC e dessas com as demais produtoras de SLCC levou essas empresas a um comportamento colaborativo entre si e com o Estado, buscando melhorias no pacote tecnológico que facultassem a melhoria na qualidade da laranja e a conseqüente maior competitividade ao SLCC no mercado internacional.

- Produtos substitutos ao SLNC - a baixa densidade da rede das empresas do GCC com os laticinistas e a alta densidade da sua rede com as demais empresas de SLCC

\footnotetext{
${ }^{9}$ Instituição mantida por produtores de laranja e empresas de suco, voltada para a defesa sanitária vegetal.
} 
desestimulavam as empresas do GCC a discutirem, com os laticinistas, alternativas que aumentassem a capacidade concorrencial do SLNC ante os substitutos.

- Potenciais novos entrantes - alta densidade com os fabricantes de SLCC e a centralidade das redes das empresas do GCC capacitavam-no a baixos custos de produção, dificultando a entrada de novos competidores.

- Eventuais baixos custos de mudança dos consumidores - a baixa densidade da rede das empresas do GCC com os laticinistas distribuidores facilitava a substituição das empresas pelos distribuidores, potencializando o fato de a baixa diferenciação do SLNC estimular a infidelidade dos consumidores.

- Eventual facilidade de acesso a canais de distribuição por parte de novos entrantes - a baixa densidade da rede dos laticinistas com as empresas do GCC facilitava a substituição desses fornecedores por outros.

Aumentos das exigências dos consumidores - a baixa densidade da rede das empresas do GCC com os laticinistas distribuidores dificultava a criação de uma filosofia de trabalho conjunto que visasse à busca de inovações na composição da bebida ou na sua apresentação ou na sua distribuição, as quais lhe alavancassem o consumo.

- Baixo poder de compra da população brasileira - função de políticas socioeconômicas governamentais, independendo das redes no setor de SLNC.

- Tradição da população brasileira pelo suco de laranja feito na hora - a baixa densidade da rede das empresas do GCC com os laticinistas distribuidores gerava a mesma falta de condições apresentada no item "Aumentos das exigências dos consumidores", as quais seriam necessárias para amenizar essa ameaça.

- Dependência em relação às marcas dos laticinistas - a baixa densidade da rede entre as empresas do GCC e os laticinistas implicava relativo desinteresse desses em perpetuar o relacionamento.

Verificou-se que, na contraposição das óticas tradicional e relacional no caso escolhido de duas empresas - aqui consideradas, por hipótese, como constituintes de um GE - no mercado brasileiro de SLNC, as redes estratégicas eram úteis para amenizar algumas das ameaças que se colocavam ao grupo quando analisado pelas cinco forças porterianas e pelos fatores macroambientais interagentes. Isso ocorria devido à alta densidade relacional e às ligações fortes entre os membros desse grupo, e entre esses e as demais empresas produtoras de SLNC, trazendo benefícios diretos e indiretos.

De forma direta, esse benefício podia ocorrer como subproduto do relacionamento muito próximo que as empresas apresentavam no mercado de SLCC, por exemplo quando uma empresa do grupo estratégico em questão necessitava de suporte no fornecimento da matéria-prima laranja, podendo recorrer a uma produtora de SLCC que, naquele momento, dispusesse da fruta. De forma indireta, esse benefício podia advir das externalidades positivas derivadas da forte representatividade política do setor de SLCC, exercida por meio da Associação Brasileira de Exportadores de Citrus (Abecitrus) ${ }^{10}$. Em outras palavras, as sinergias freqüentemente observadas entre os negócios de SLCC e de SLNC, a grande

10 Entidade que representa as empresas produtoras de SLCC. 
interdependência que existia entre as empresas produtoras de SLCC (MARGARIDO, 1996) e o próprio fato de o setor de SLCC apresentar características de coordenação setorial reforçavam, continuamente, as vantagens que as empresas do referido grupo detinham no sub-setor de SLNC. Por outro lado, no caso das relações entre esse grupo e os laticinistas, a baixa densidade e as ligações fracas que ali se verificam eram, recorrentemente, identificadas como as responsáveis pela incapacidade de o grupo enfrentar ameaças que se lhe colocavam nesse mercado, notadamente no caso dos substitutos. Isso porque, na medida em que os consumidores ainda tendiam a ver o suco de laranja como uma bebida refrescante e não como um alimento, o SLNC passava ter de disputar mercado com os refrigerantes, com os repositores de energia ${ }^{11}$ e com os isotônicos. Estes, por sua vez, contavam com vários trunfos para alcançar os consumidores: diversas opções de apresentação (embalagens variadas, versões light e diversos sabores no caso dos refrigerantes), invejável capilaridade distributiva (principalmente refrigerantes), desnecessidade de armazenagem a frio (todos), baixo preço (caso dos repositores de energia) e marketing muito agressivo (caso dos refrigerantes e isotônicos).

Maior integração dos fabricantes de SLNC com os distribuidores seria o primeiro passo para que essa bebida pudesse passar a contar com pelo menos uma parte dessa variedade de apelos. Por exemplo, os distribuidores poderiam alimentar os fabricantes com informações oriundas da ponta varejista, que servissem como subsídios para novas soluções na elaboração e a apresentação do SLNC que alavancassem as vendas. Cabe notar, também, que esses atributos negativos na rede entre as empresas do GCC e os laticinistas eram potencializados pelas acentuadas densidade e força das ligações que existiam na rede entre elas e as demais empresas produtoras do SLCC, criando o risco de desestimular as do GCC a permanecerem no mercado de SLNC - como se verificou, na prática, em fins de 2001, no caso da Citrovita.

\section{CONCLUSÕES}

Neste artigo, destacou-se de que forma as redes estratégicas, em especial as de agrupamentos de empresas estruturalmente similares e conectadas mais densamente entre si (ou seja, blocos estratégicos), podem levar à releitura ou à complementação de análises tradicionais relativas à competitividade de grupos estratégicos, porquanto capacitam as empresas a adentrarem esses grupos sem o constrangimento ditado pelas barreiras de mobilidade.

Utilizando construtos relacionais pertinentes à ereção de barreiras de mobilidade, lançou-se mão de caso concreto de empresas do sub-setor da agroindústria brasileira de SLNC que, a partir de análise documental, foram consideradas, por hipótese, como constituindo um GE. Com isso, compararam-se as oportunidades e ameaças definidas, respectivamente, pelas óticas relacional e tradicional. Assim, foi possível verificar que a perspectiva relacional dá margem tanto a ameaças como a oportunidades ao desempenho estratégico empresarial, dificilmente identificadas apenas pela ótica tradicional.

A contribuição deste artigo reside nessa visão complementar à tradicional, suprindo as eventuais limitações das análises referentes a grupos estratégicos, ao identificar que as redes podem amenizar as ameaças impostas às empresas do grupo pela ação das cinco forças porterianas e dos fatores macroambientais interagentes. De fato, o caso escolhido para a aplicação dessa nova ótica sugeriu que a redução dessas ameaças é contingente à presença de

\footnotetext{
${ }^{11}$ Denominação das bebidas compostas majoritariamente por água e açúcar, com sabores que remetem, por exemplo, à laranja ou ao guaraná.
} 
fatores relacionais, tais como a alta densidade e a acentuada intensidade das ligações na rede do grupo Cargill/Citrovita. Ou seja, a releitura proposta reside na visão de que ameaças e oportunidades observadas pela ótica tradicional podem sofrer alterações a partir da influência das redes de relacionamento.

A implicação desse resultado para a tomada de decisão estratégica, no caso das empresas aqui consideradas como grupo estratégico, é que, em vez de entrarem no mercado de suco de laranja não concentrado com simples acordos de distribuição, deveriam ter-se orientado estrategicamente no sentido de formar uma aliança estratégica entre o fabricante e o distribuidor.

Apoiando-se nesse caso concreto, formulou-se a seguinte proposição: quando uma empresa de um grupo estratégico está em rede em mais de um mercado, cujos graus de importância diferem muito entre si, dependendo das características da aliança estabelecida no mercado de menor importância, a ocorrência de fatores exógenos pode interferir sobre as redes ali existentes a ponto de destruí-las, levando a mudança na configuração dos atores no setor industrial do grupo enfocado.

\section{REFERÊNCIAS BIBLIOGRÁFICAS}

ANAND, B.N.; KHANNA, T. Do firms learn to create value? The case of alliances. Strategic Management Journal, v.21, n. 4, abril, p.295-315, 2000.

AUSTIN, James E. Managing in developing countries: strategic analysis and operating techniques. New York: The Free Press, 1990.

AZEVEDO, P.F. Integração vertical e barganha. 1996. Tese (Doutorado em Economia) Faculdade de Economia, Administração e Contabilidade da Universidade de São Paulo, São Paulo, São Paulo, Brasil.

AZEVEDO, P.F. Integração vertical parcial no sistema agroindustrial citrícola: instrumento de barganha ou de eficiência? Economia Aplicada, São Paulo, v.1, n.3, março, p. 30-35, 1997.

BARNEY, Jay B. Gaining and sustaining competitive advantage. Massachusetts: AddisonWesley, 1996.

CAVES, R.E.; PORTER, M.E. From entry barriers to mobility barriers: conjectural decisions and contrived deterrence to new competition. Quarterly Journal of Economics, v.91, n. 9, setembro, p.241-262, 1977.

COLEMAN, J.S. Social capital in the creation of human capital. American Journal of Sociology, v.94 (Supplement), n. 5, maio, p.95-120, 1988.

COOL, K.; SCHENDEL, D. Strategic group formation and performance: the case of the U.S. pharmaceutical industry, 1963-1982. Management Science, v.33, n.9, p.1102-1124, 1987.

DI GIORGI, Fábio. Mitos da citricultura: ruptura e modernização. Laranja, Cordeirópolis: Centro de Citricultura Silvio Moreira, v.15, n.2, setembro, p.85-95, 1994. 